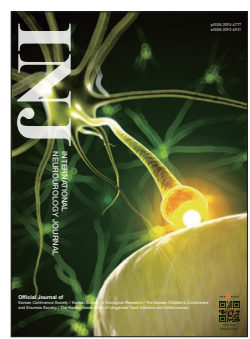

\title{
Basic Research as the Top Priority for INJ
}

\author{
Tack Lee (iD http://orcid.org/0000-0001-8508-9099 \\ Editor-in-Chief \\ Department of Urology, Inha University Hospital, Incheon, Korea \\ E-mail: lee.tack33@gmail.com
}

This year marks the 20th anniversary of the International Neurourology Journal (INJ). I am truly honored to be working as the fifth Editor-in-Chief of this journal. Those of you who are old enough to remember the original journal written in Korean have seen many changes over the last 7 years. In 2010, the journal's language was changed from Korean to English and from 2012, the journal was selected to be indexed in Thompson Reuters' Science Citation Index Expanded accessed via the Web of Science. The journal has also changed in size from a quarterly publication to being published 6 times a year including 2 supplementary issues. In 2010, around 40 articles were published; this has now risen to 78 articles in 2016. The impact factor of the journal continues to rise (1.344 in 2015) due to the hard work and cooperation of a talented group of professionals that includes our editorial board with a range of editorial specialists in all areas of neurourology, a dedicated editorial office staff, credible academic partners, and the busy professionals who volunteer their time as peer reviewers for INJ.

In particular, I would like to express my appreciation for Dr. Hong-Sang Moon, the associate editor, for his unwavering support. He has been an editorial board member of the journal for a number of years, bringing with him an extensive background in neurourology and a wealth of experience. I am sorry to report that Dr. Moon will be temporarily stepping down from his position as the associate editor due to a health problem, although he will return when this problem is resolved.

To cope with the increasing and changing demands of the journal, INJ has restructured its editorial board format, and Dr.
Young Sam Cho, and Dr. Khae Hawn Kim will join us as the new associate editors in 2017. They will compose a new team consisting of multiple editors with various perspectives and methodological skills. In the future, we hope to attract more editors with international expertise.

The essence of science is to uncover, through careful observation, patterns and regularities in nature. The role of a journal is to objectively deliver these findings to readers worldwide, which then enables other researchers to replicate and advance the results. Thus, objectivity is of utmost importance, as scientific fraud can mislead other researchers, wasting precious time and money with replication efforts. Consequently, our journal will require the original unprocessed data from the authors in all accepted manuscripts prior to publication.

Clinical practice is always built on a solid foundation of basic research. Our journal aims to deliver the knowledge and discoveries gained from basic science to medical practice. Thus, although our journal is for clinicians, basic research is our top priority. INJ sets itself apart from other clinical journals through accepting basic research not only in urology, but also from other fields that can help solve the mystery of the bladder. For this reason, we welcome valuable basic research articles from outside as well as within the scope of urology, thereby introducing the results to clinical neurourology as soon as possible.

- Conflict of Interest: No potential conflict of interest relevant to this article was reported. 